\title{
Experimental Investigation of the Helical Condenser for Humidification Dehumidification Desalination Unit Powered by Solar Energy
}

\author{
K. Elsawy", I.A. Ibrahim, A. Abdelmotalip, Y. Elhenawy \\ Mechanical Power Engineering Department, Port-Said University, Egypt
}

Received: 19/10/2020

Accepted: 25/12/2020

Published: 20/06/2021

\begin{abstract}
In this paper, built the water desalination unit based on the humidification dehumidification (HDH) process powered by solar energy was examined. The unit uses a humidifier of the packing type (HPT) and the dehumidifier (condenser) made a concentric helically tube and shell heat exchanger was investigated. The dehumidifier was used to condensate water vapor from humid air. The Nusselt number (Nu) inside the helical tube was discussed in many studies before, although it is not mentioned before the Nusselt number outside the helical tube for a mixture fluid. In the current study cold water in passing inside a concentric helical tube, while a hot humid air passing over the external surface of the concentric helical tube. The concentric helical tube is positioned inside an insulated shell. Different air flowrates were used, and the experimental results were used to induce a new empirical equation for the shell's Nusselt number. The water desalination unit was examined by using the solar collectors as a heating source for the saline feed water and the introduced air to the humidifier, and it is found that the freshwater productivity was $8.60 \mathrm{~kg} /$ day and to reduce the carbon dioxide released by $4600 \mathrm{~g} / \mathrm{day}$.
\end{abstract}

Keywords: Humidification dehumidification process, Packing, Helical condenser, Solar energy, Desalination

\section{Introduction}

Heat exchangers are employed widely in different applications. Improving heat transfer leads to reduce the heat exchanger size. Two methods employ to better the heat transfer of heat exchangers by using forced and passive methods. The passive method requires fluid additives or appropriate surface geometries, while the active technique requires external actions like surface vibration, fluid vibration, and electric field. Helically coiled tubes were discussed in many studies and the centrifugal force effect, generated due to the curvature of the tubes was investigated. Moawed [1] investigated experimentally the active heat transfer from outside surfaces of helically coiled tubes at the constant heat flux. The researcher made his experiments on ten helical coiled tubes with different values of $\mathrm{D} / \mathrm{do}$ and $\mathrm{p} / \mathrm{do}$ in the wind tunnel systemThe experimental data cased an order of Reynolds number (Re) $6.6 \leq \operatorname{Re} \leq 2.3 \times 10^{3}$. The outcomes showed that the maximum values of $\mathrm{Nu}$ can be obtained with a maximum value of $\mathrm{D} / \mathrm{do}$, and with a lower value of $\mathrm{p} / \mathrm{do}$. A common correlation of the average $\mathrm{Nu}$ is get as follows:

$N u=0.0345 R e^{0.48}\left(D / d_{o}\right)^{0.914}\left(p / d_{o}\right)^{0.281}$

$6.6 \times 10^{2} \leq R e \leq 2.3 \times 10^{3}$

$$
\begin{aligned}
& 7.086 \leq D / d_{o} \leq 16.142 \\
& 1.81 \leq p / d_{o} \leq 3.205
\end{aligned}
$$

Several studies investigated the helical condenser performance and the effect of the centrifugal force generated due to the tube curvature. Nadia Essalhi et al. [2] investigated a suitable method to obtain an accurate value of the condensation coefficient of the heat transfer outside the helical coil. The researchers mentioned that there are not many types of research to indicate the condensation coefficient of the heat transfer around the helical coil, so they assumed that the condensation coefficient of the heat transfer around horizontal tubes can be the same as the coefficient of the heat transfer for the helical coil. The researchers investigated this phenomenon by performing their experiments on a chiller that operated with an $\mathrm{H} 2 \mathrm{o} / \mathrm{LiBr}$ combined refrigerant. Salimpour [3] indicated in this study the heat transfer coefficients of the spiral tube and tube heat exchangers. The researcher built 3 heat exchangers with completely different winding heights for each of the counter flow and parallel current configurations. The researcher performed 75 test runs on three heat exchangers and the heat transfer coefficients for the casing and coil were also calculated. The results indicated that the shell facet heat transfer coefficients of the coils with larger pitches are more than those 
for smaller pitches. Two correlations for heat transfer coefficients are also developed. Shirgire and Kumar [4] in this study established a comparison between the straight tube heat exchanger and the helical coil heat exchanger. The researchers studied the heat transfer coefficients of the helical coil heat exchanger and compared it to the straight tube heat exchanger. The results indicated that the heat transfer in helical tubes is higher than the heat transfer in straight tubes due to their shapes. Centrifugal forces are generated helically because of the bends and these centrifugal forces develop a secondary flow which improves heat transfer. Moradi and Veysi [5] investigated the heat transfer of jackets and helically wound tubular heat exchangers using experimental and numerical methods. The influence of the physical properties of the fluid, operating parameters, and geometric parameters on the $\mathrm{Nu}$ of both sides was investigated. The researchers predicted two correlations for $\mathrm{Nu}$ on the coil side and on the shell side for various ranges of Reynolds and Prandtl numbers. It was found that these two correlations agreed well with the experimental data of operating and geometric parameters. The results of the experiments indicated that the pitch size doesn't have an effect on the coil side's Nu while increasing the pitch size increases the shell side's $\mathrm{Nu}$. It was noticed that increasing the tube diameter with constant velocities and geometrical parameters, increases the Nusselt numbers for both sides. Increasing the coil diameter increases the overall coefficient of heat transfer. Finally increasing the length and the radius of the shell decreases the shell side's Nusselt number. S.B.Genic et al. [6] experimental study the heat transfer coefficient of the shell side of the helically coiled and shell. Three heat exchangers with helical coils were used in these experiments in the laboratory. The researcher used in the experiments the hot water and the cold water as the working fluids. The researchers indicated the thermal performance on the 3 heat exchangers with concentric helical coils and the results indicated that the geometrical parameters like (axial pitch, winding angles, radial pitch, etc.) is affecting the shell side heat transfer coefficient. In the end of their experiments, the researchers predicted a new correlation for shell side heat transfer coefficient based on shell hydraulic diameter. N.Jamshidi et al.[7] demonstrated the heat transfer characteristics in the shell and helical tube heat exchangers and the optimum design parameters in coiled tube heat exchangers. The researchers used the Wilson plot and Taguchi method to study the coefficients of heat transfer and to indicate the optimum design parameters. A helically coiled heat exchanger was used where the helical coil was made from copper and the helical coil had ten runs. The operating fluids used were hot water inside the coiled tube and cold water on the shell side. The results showed that the $\mathrm{Nu}$ improved by increasing the shell side flowrate while increasing the coil pitch increases the shell side $\mathrm{Nu}$ and decreases the coiled tube side $\mathrm{Nu}$ and overall heat transfer coefficients increase, while the shell side $\mathrm{Nu}$ decreases. Finally, the overall coefficient of heat transfer in the coiled tube heat exchanger can be increased by the maximum level of the coil radius, coil pitch, flow rates of hot and cold water. N.Ghorbani et al. [8] investigated tested the mixed heat transfer by convection in heat exchanger from the helical coiled tube type. The researchers made their experiments for each laminar and turbulent flow inside the coil. The researchers studied the influence of coil pitch and tube raduiss on the shell side heat transfer coefficient of the heat exchanger. The outcomes indicated that the coil surface area has a negative effect on the shell side heat transfer coefficient while increasing the coil pitch increases the shell side coefficient of heat transfer. The results showed that the equivalent diameter of the shell is the best characteristic length to evaluate the Nusselt number by using the Rayleigh and Reynolds numbers.

Based on previous studies, investigated the performance of the helical heat exchanger and the effect of the centrifugal force generated due to the tube curvature. The Nusselt number inside the helical tube was discussed in many studies before, although it is not mentioned before the Nusselt number outside the helical tube for a mixture fluid. The recent study is aiming to introduce an empirical equation of the shell's Nuselt number. A helical shell and tube heat exchanger was used to condensate vapor water from humid air and the experimental results were discussed to get the empirical equation.

\section{Experimental set up and procedure 2.1 System description}

A solar desalination unit based on a humidification and dehumidification process was designed and constructed as shown Fig.1. The cycle is equipped, mainly, by $\mathrm{V}$-groove air collector, a flat plate water collector, a humidifier and a dehumidifier. In present work, the brine heater is a flat plate solar collector. The solar water collector area is $2 \mathrm{~m}^{2}$ with a surface angle of $30^{\circ}$. The dimension of solar air collector is $1.15 \times 2.3 \times 0.25 \mathrm{~m}$ and placed at a surface angle of $30^{\circ}$. A shell and helical tube heat exchanger (dehumidifier) was tested to gain the heat transfer coefficient on the outside surface of a double concentric helical coil. The heat exchanger is used in water desalination experiment to condense a hot humid air, which is generated by direct mixing between dry air and hot saline water. The freshwater is produced from condensing the hot humid air. The heat exchanger consists of a PVC pipe with a length of $75 \mathrm{~cm}$ and a diameter of $22 \mathrm{~cm}$. A copper helical coil, Fig 2 is used inside the pipe to cool the humid hot air and condensate the water vapor to obtain fresh water. The coil has $11.1 \mathrm{~mm}$ inside diameter and $12.7 \mathrm{~mm}$ outside diameter and $30 \mathrm{~m}$ length. Coldwater is obtained from the cooling tank (2000 liter) by using a centrifugal cooling pump (0.5HP provides a maximum flow rate of $8 \mathrm{~L} / \mathrm{min}$ ) to be introduced inside the helical coil. The heat exchanger is in a vertical position during experiments.

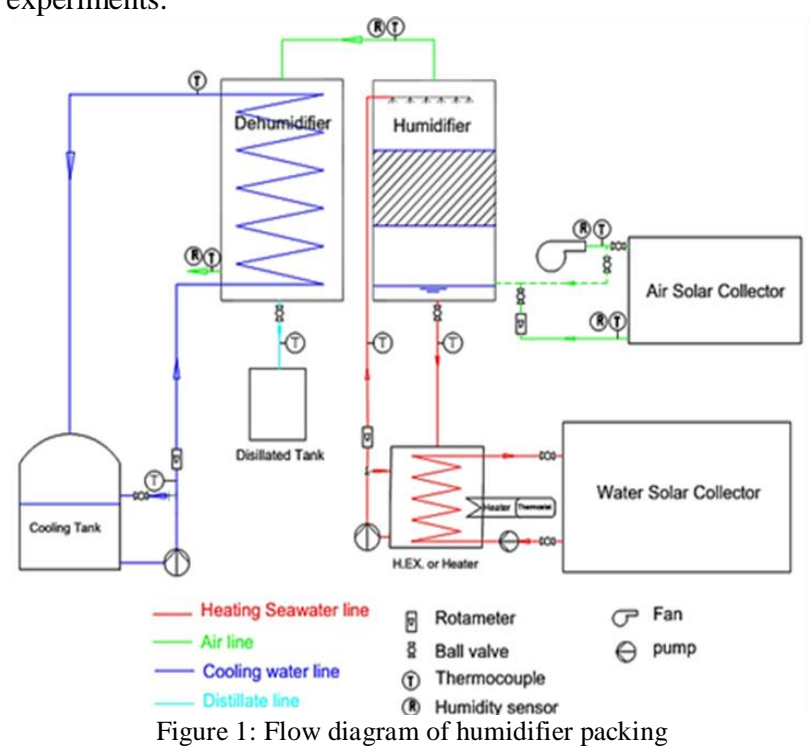




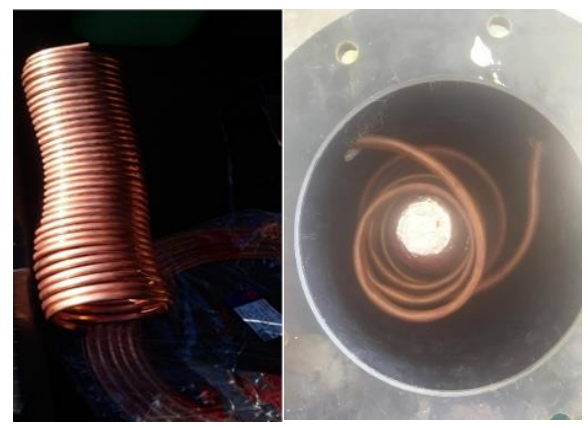

Figure.2: Shell and helical tube heat exchanger

\subsection{Measuring instruments}

A Rotameter (HFB-2-05, Dwyer, UK with NPT fitting) was used to measure the flow rate inside the coil. The flow rate range is from 1 LPM to 19 LPM with an accuracy of $\pm 1 \%$. The flow rate inside the shell was measured by use of KDG Houdec model $134 / 47$ range of $(0-80) \mathrm{m}^{3} / \mathrm{h}$, Temperature: $\max .200^{\circ} \mathrm{C}$. K type thermocouples were used in: (a) inlet and outlet of the coil (i.e. $\mathrm{T} 1$ and T2). These thermocouples were inserted into small holes made in the inlet and outlet plastic tubes of the coil side and sealed to prevent any leakage and (b) inlet, outlet the shell (i.e. T3 and T4). The process for installation of T3 and T4 is like that used for T1 and T2. A Data logger (Model: Midi LOGGER (GL820)) is used to record these temperatures. The dew point, wet bulb temperature and RH can be measured by testo 625 compact Thermo hygrometer. Six experiments were held at different airflow rates and different air temperatures to derive an empirical equation for the outside heat transfer coefficient over the concentrated double coil. Coldwater is pumped inside the helical coil while the hot humid air is introduced inside the shell. The following table (table 1) is illustrating the input parameters and the results obtained from the experiments:

Table 1: The input parameters and results obtained from the experiments

\begin{tabular}{|c|c|c|c|c|c|c|c|c|c|c|}
\hline No & $\begin{array}{c}\mathrm{m}_{\mathrm{w}} \\
\mathrm{L} / \mathrm{min}\end{array}$ & $\begin{array}{c}\mathrm{m}_{\mathrm{a}} \mathrm{m}^{3} / \mathrm{hr} \\
\mathrm{m}^{3} / \mathrm{m}_{\mathrm{w}} /\end{array}$ & $\begin{array}{c}\mathrm{m}_{\text {cool }} \\
\mathrm{m}_{\mathrm{a}}\end{array}$ & $\begin{array}{c}\mathrm{T}_{\mathrm{cw}, \mathrm{i}} \\
\mathrm{Lin}\end{array}$ & $\begin{array}{c}\mathrm{T}_{\mathrm{cw}, \mathrm{o}} \mathrm{C} \\
{ }^{\circ} \mathrm{C}\end{array}$ & $\begin{array}{c}\mathrm{T}_{\mathrm{a}, \mathrm{i}} \\
{ }^{\circ} \mathrm{C}\end{array}$ & $\begin{array}{c}\mathrm{T}_{\mathrm{a}, \mathrm{o}} \\
{ }^{\circ} \mathrm{C}\end{array}$ & $\emptyset_{\mathrm{a}, \mathrm{i}}$ & $\begin{array}{c}\mathrm{W}_{\mathrm{p}} \\
\mathrm{gm}\end{array}$ \\
\hline 1 & 3.1 & 52 & 3 & 4.6 & 20.83 & 22.42 & 30.17 & 23.45 & 99 & 255 \\
\hline 2 & 3.1 & 26 & 6 & 4.6 & 21.42 & 24 & 33.25 & 25.08 & 99 & 140 \\
\hline 3 & 3.1 & 52 & 3 & 4.6 & 22.58 & 26.08 & 36.83 & 27.42 & 99 & 355 \\
\hline 5 & 3.1 & 26 & 6 & 4.6 & 25.42 & 27.33 & 40.58 & 29.08 & 99 & 195 \\
\hline 6 & 3.1 & 52 & 3 & 4.6 & 20.33 & 25.42 & 42.75 & 26.17 & 99 & 790 \\
\hline
\end{tabular}

Where m.w is the hot saline water mass flow rate, m.a is the air mass flowrate, m.cool is the cooling water mass flow rate, Tcw, $\mathrm{i}$ is the cooling water temperature at coil inlet, Tcw,o is cooling water temperature at coil outlet, Ta,i is the hot humid air temperature at shell inlet, Ta,o is the condensed air temperature at shell outlet and $\mathrm{Wp}$ is the water productivity. Each experiment took 30 minutes and then the condensed water vapor was being weighted. After the hot dry air is being humid by direct mixing with hot saline water, it passes over the helical coil where a heat exchanging is happening between the cold surface of the helical coil and the hot humid air. Every 5 minutes the temperatures of cooling water at inlet and outlet and the temperatures of humid air at inlet and outlet were recorded. The average temperature for each point was recorded during the 30 minutes as illustrated in the previous table.

\section{Uncertainty analysis}

The following expression is used to evaluate the standard uncertainties for the instrumentation used in experiments $[9,10]$ :

$u=a / \sqrt{3}$

where the instrument accuracy is a and the standard uncertainty is u. Table 2 gives standard uncertainty and Instruments accurateness.

Table 2: Standard uncertainties and Instruments accurateness

\begin{tabular}{llll}
\hline Device & Accuracy & Range & $\begin{array}{l}\text { Standard } \\
\text { Uncertainty }\end{array}$ \\
\hline Thermocouple & $0.15^{\circ} \mathrm{C}$ & $0-150{ }^{\circ} \mathrm{C}$ & $8.67 \times 10^{-2}{ }^{\circ} \mathrm{C}$ \\
Rotameter & $0.2 \mathrm{~L} / \mathrm{min}$ & $15 \mathrm{~L} / \mathrm{min}$ & $0.06 \mathrm{~L} / \mathrm{min}$ \\
$\begin{array}{l}\text { Pressure } \\
\text { transducer }\end{array}$ & $0.013 \mathrm{bar}$ & $0-3 \mathrm{bar}$ & $7.5 \times 10^{-3} \mathrm{bar}$ \\
Balance & $0.4 \mathrm{~g}$ & 1 to $25000 \mathrm{~g}$ & $0.251 \mathrm{~g}$ \\
\hline
\end{tabular}

\section{Mathematical model}

The total amount of heat transferred from coil side is evaluated based on the mass flow rate, $m^{o}$, the specific heat of water, $C_{p}$, and the difference in inlet temperature, $T_{c i}$, and outlet temperature, $T_{c 0}$, given by $[11,12,13]$ :

$Q_{c}=m^{o} C_{p}\left(T_{c i}-T_{c 0}\right)$

The mass flow rate of cold water is calculated as:

$m^{o}=\rho_{i} V^{\circ}$

where $V^{\circ}$ is the volumetric flow rate $\left(\frac{m^{3}}{s}\right)$ and $\rho_{i}$ is the water density at coil side average temperature $\frac{\left(T_{c i}+T_{c 0}\right)}{2} \quad\left(\frac{K g}{m^{3}}\right)$. The heat transfer rate $Q_{c}$ is then used to calculate the outside condenser area.

$A_{o}=\frac{Q_{C}}{U T_{L M T D}}$

where, $T_{L M T D}$ is the log-mean temperature difference $(\mathrm{K})$ and it is calculated for the counter flow as:

$T_{L M T D}=\frac{\left(T_{h, i}-T_{c, o}\right)-\left(T_{h, o}-T_{c, i}\right)}{\ln \frac{\left(T_{h, i}-T_{c, o}\right)}{\left(T_{h, o}-T_{c, i}\right)}}$

and $U_{o}$ is the overall heat transfer coefficient

$\frac{1}{U_{o} A_{o}}=\frac{1}{h_{i} A_{i}}+\frac{\ln \left(d_{o} / d_{i}\right)}{2 \pi k_{\text {coil }} l}+\frac{1}{h_{o} A_{o}}$

where, $h_{i}$ is internal heat transfer coefficient inside the coil $\left(W / m^{2} . K\right), d_{i}$ is inside diameter of the coiled tube $(m), d_{o}$ is 
outside diameter of the coiled tube $(m), A_{i}$ is inside area of the coiled tube $\left(\mathrm{m}^{2}\right), A_{i}=\pi d_{i} l$ where $t$ is thickness of coil, $l$ is length of the coiled tube $(m)$ and $k_{\text {coil }}$ is thermal conductivity of coiled tube $(W / m . K)$. To calculate $h_{i}$ and $h_{o}$ the Nusselt number inside the helical coil and outside the helical coil must be calculated. Many studies made experiments on helical coil to calculate the heat transfer coefficients. To calculate the heat transfer coefficient at coil side, the following equations are used [14, 15, 16]: The critical Reynolds No. for helical tubes, $R e_{\text {critical }}$, related to the curvature ratio is given as:

$R e_{\text {critical }}=2300\left[1+8.6\left(\frac{r_{i}}{R_{c}}\right)^{0.45}\right]$

For laminar regime:

$N u_{i}$

$=3.65$

$+0.08\left[1+0.8\left(\frac{r_{i}}{R_{c}}\right)^{0.9}\right] \cdot R e^{\left[0.5+0.2903\left(\frac{r_{i}}{R_{c}}\right)^{0.194}\right]} \cdot \operatorname{Pr}^{\frac{1}{3}}$

where Reynolds number varies $100<R e<R e_{\text {crit }}$

For turbulent flow:

$N u_{i}=0.021\left(\frac{r_{i}}{R_{c}}\right)^{0.1} \cdot \operatorname{Re}^{0.85} \cdot \operatorname{Pr}^{0.4}$

where, $P r$ is the Prandtl number, $R e$ is the Reynolds number $=$ $\frac{\rho_{i} v_{i} d_{i}}{\mu_{i}}$ and $\mu_{i}$ is the water dynamic viscosity at coil side average temperature $\left(N . s / \mathrm{m}^{2}\right), v_{i}$ is water velocity inside coiled tube $(\mathrm{m} / \mathrm{s})$ and $\rho_{i}$ is the water density at coil side average temperature $\left(\mathrm{Kg} / \mathrm{m}^{3}\right), r_{i}$ is the inside radius of the tube $(\mathrm{m})$ and $R_{c}$ is the radius of the coil $(m)$.

$h_{i}=\frac{N u_{i} k_{i}}{d_{i}}$

where, $k_{i}$ is the thermal conductivity of cold water inside the coils. For multi concentric coils, the total heat transfer coefficient can be treated like the electrical resistances as following [17, 18]: For parallel connecting coils (the flow inside the coil is divided on the concentric coils).

$h_{\text {i.total }}=\frac{h_{1} A_{1}+h_{2} A_{2}+\cdots h_{m} A_{m}}{A_{\text {total }}}$

For series connecting coils (the flow inside the coil is the same in every coil).

$h_{i, \text { total }}=\frac{h_{1} h_{2} A_{1} A_{2} \ldots \ldots h_{m} A_{m}}{A_{\text {total }}\left(h_{1} A_{1}+h_{2} A_{2}+\cdots+h_{m} A_{m}\right)}$

where " $\mathrm{m}$ " is the number of coils. To calculate the heat transfer coefficient at shell side $\mathrm{h}_{-} \mathrm{o}$, we have to make an empirical correlation as no many types of research at this point. To find this correlation, we have to use the Buckingham pi theorem to get a general correlation for the Nusselt number at the shell side then solving it by any regression analysis on the collected data from experiments $[19,20]$. The hydraulic diameter $D_{\text {hyd }}$ is defined as the "characteristic length" used to calculate the dimensionless Reynolds Number to determine if the flow is turbulent or laminar, determine the value of Nusselt number and calculate the pressure loss in ducts or pipes. The hydraulic diameter in the heat exchanger used in the experiments is based upon a projected cross-section as shown in Figure 3.

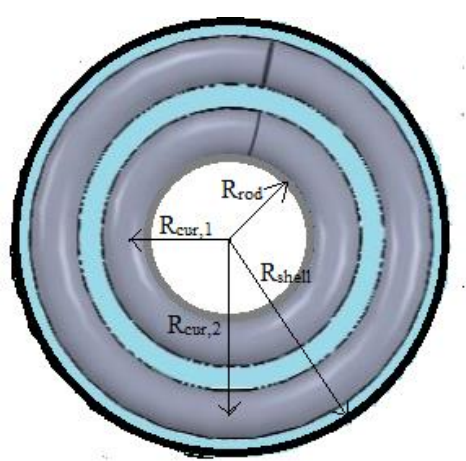

Figure 3: The heat exchanger projected cross section, blue areas indicate flow cross-section

The hydraulic diameter is calculated as following [17]:

$$
\begin{aligned}
& \mathrm{A}_{\mathrm{cs}, \text { shell }}=\frac{\pi}{4}\left(\mathrm{D}_{\text {shell }}\right)^{2} \\
& A_{c s, \text { coil } 1}=\frac{\pi}{4}\left(\left(D_{c u r, 1}+d_{o}\right)^{2}-\left(D_{c u r, 1}-d_{o}\right)^{2}\right) \\
& A_{c s, \text { coil } 2}=\frac{\pi}{4}\left(\left(D_{\text {cur }, 2}+d_{o}\right)^{2}-\left(D_{c u r, 2}-d_{o}\right)^{2}\right) \\
& A_{c s, \text { rod }}=\frac{\pi}{4}\left(D_{\text {rod }}\right)^{2} \\
& P_{\text {wet, shell }}=\pi D_{\text {shell }} \\
& P_{\text {wet }, \text { coil } 1}=\pi\left(\left(D_{c u r, 1}+d_{o}\right)+\left(D_{c u r, 1}-d_{o}\right)\right) \\
& P_{\text {wet }, \text { coil } 2}=\pi\left(\left(D_{c u r, 2}+d_{o}\right)+\left(D_{c u r, 2}-d_{o}\right)\right) \\
& P_{\text {wet }, \text { rod }}=\pi D_{\text {rod }} \\
& D_{\text {hyd }}=\frac{4\left[A_{c s, \text { shell }}-A_{c s, \text { coil 1 }}-A_{c s, \text { coil 2 }}-A_{c s, \text { rod }}\right]}{P_{\text {wet }, \text { shell }}+P_{\text {wet,coil 1 }}+P_{\text {wet }, \text { coil } 2}+P_{\text {wet,rod }}}
\end{aligned}
$$

where $\mathrm{A}_{\mathrm{cs}}$ is the cross-sectional area $\left(\mathrm{m}^{2}\right)$ and $\mathrm{P}_{\text {wet }}$ is the wetted perimeter $(m)$. By applying Buckingham pi theorem, the following dimensionless groups are generated:

$\pi_{1}=N u_{\text {mix }}, \pi_{2}=R e_{\text {mix }}, \pi_{3}=P r_{\text {mix }}$

As rearranging the groups, the final correlation as:

$$
\begin{aligned}
& N u_{\text {mix }}=f\left(P r_{\text {mix }}, R e_{\text {mix }}\right) \\
& N u_{\text {mix }}=\mathrm{A}\left(\operatorname{Re}_{\text {mix }}\right)^{\mathrm{a}}\left(\operatorname{Pr}_{\text {mix }}\right)^{\mathrm{b}}
\end{aligned}
$$


where subscript 'mix' refers to the humid air (mixture of air and water vapor). To calculate $P r_{\text {mix }} \& R e_{\text {mix }}$ the thermophysical properties used must be those for an air and water vapor mixture $[21,22]$. Assuming that both the water vapor and the dry air behave as ideal gases, the volumetric thermal expansion coefficient is simply the inverse of the absolute temperature. For moist air, the mixture molar mass $M_{\text {mix }}\left(\frac{\mathrm{Kg}}{\mathrm{mol}}\right)$ can be calculated using:

$M_{\text {mix }}=X_{a} M_{a}+X_{v} M_{v}$

where the mole fraction for the dry air $X_{a}$ and water vapor $X_{v}$ is calculated using:

$X_{a}=\frac{P-\emptyset P_{g}}{P}$

$X_{v}=\frac{\emptyset P_{g}}{P}$

$\emptyset=\frac{P_{v}}{P_{g}}$

where $P_{g}$ is saturation pressure of water vapor at temperature T and can be calculated from the August-Roche-Magnus formula:

$P_{g}=0.61094 \exp \left(\frac{17.625 T}{T+243.04}\right)$

where temperature $T$ is in ${ }^{\circ} \mathrm{C}$ and vapor pressure $P_{g}$ is in kilopascals $(\mathrm{kPa}), P_{v}$ is water vapor pressure and $\mathrm{P}$ is the total pressure of the mixture and calculated as the sum of partial pressure of dry air and water vapor:

$P=P_{a}+P_{v}$

and the mixture gas constant $R_{\text {mix }}\left(\frac{J}{K g . K}\right)$ via:

$R_{\text {mix }}=\frac{R_{u}}{M_{\text {mix }}}$

where, $R_{u}\left(\frac{J}{\text { K.mol }}\right)$ is the universal gas constant.

The mixture density $\rho_{\text {mix }}\left(\mathrm{Kg} / \mathrm{m}^{3}\right)$ is determined using:

$\rho_{\text {mix }}=\frac{P}{R_{\text {mix }} T}$

while $T$ is the film temperature (the average temperature of the body surface and the moist air environment). The mixture constant pressure-specific heat $c_{p, \text { mix }}\left(\frac{\mathrm{J}}{\mathrm{Kg} \cdot \mathrm{K}}\right)$ is calculated as:

$c_{p, \text { mix }}=Y_{a} c_{p, a}+Y_{v} c_{p, v}$

where the specific heat for each individual component is determined using the following polynomial expression: $c_{p, i}=\frac{1}{M_{i}}\left(a_{i}+b_{i} T+c_{i} T^{2}+d_{i} T^{3}\right)$

Table 3 provides the respective of the molar mass for water vapor and dry air as well as the respective values of the coefficients.

Table 3: Constant pressure specific heat polynomial coefficients

\begin{tabular}{llllll}
\hline & $M_{i}$ & $\mathrm{~A}$ & $\mathrm{~b}$ & $\mathrm{c}$ & $\mathrm{d}$ \\
\hline$c_{p, a}$ & 28.97 & 28.11 & $0.1967 *$ & $0.4802 *$ & -1.966 \\
& & & $10^{-2}$ & $10^{-5}$ & $* 10^{-9}$ \\
$c_{p, v}$ & 18.015 & \multirow{2}{*}{32.24} & $0.1923 *$ & $1.055 *$ & -3.595 \\
& & & $10^{-2}$ & $10^{-5}$ & $* 10^{-9}$ \\
\hline
\end{tabular}

The mass fraction of the dry air $Y_{a}$ and water vapor $Y_{v}$ may thus be respectively calculated using:

$$
\begin{gathered}
Y_{a}=\frac{P-\emptyset P_{g}}{P+\left(\frac{R_{a}}{R_{v}}-1\right) \emptyset P_{g}} \\
Y_{v}=\frac{\emptyset P_{g}}{\frac{R_{v}}{R_{a}} P+\left(1-\frac{R_{v}}{R_{a}}\right) \emptyset P_{g}}
\end{gathered}
$$

where, $R_{a}\left(\frac{\mathrm{J}}{\mathrm{kg} \cdot \mathrm{K}}\right)$ is the gas constant for dry air and $R_{v}\left(\frac{\mathrm{J}}{\mathrm{kg} \cdot \mathrm{K}}\right)$ is the gas constant for water vapour. For both water vapour and dry air, the behaviour of the thermal conductivity and the dynamic viscosity are assumed to follow a power law relationship, i.e.,

$k_{i}=k_{o, i}\left(\frac{T}{T_{o}}\right)^{n_{k, i}}$

$\mu_{i}=\mu_{o, i}\left(\frac{T}{T_{o}}\right)^{n_{\mu, i}}$

Table 4 indicates the required power law properties for thermal conductivity, while the power law properties for viscosity are indicated in Table 5.

Table 4: Power law parameters for thermal conductivity.

\begin{tabular}{lllc}
\hline & $k_{o}(\mathrm{~W} / \mathrm{m} \mathrm{K})$ & $T_{o}(\mathrm{~K})$ & $n_{k}$ \\
\hline$k_{a}$ & 0.0241 & 273 & 0.81 \\
$k_{v}$ & 0.0181 & 300 & 1.35 \\
\hline
\end{tabular}

Table 5: Power law parameters for viscosity

\begin{tabular}{llll}
\hline & $\mu_{o}\left(\mathrm{Ns} / \mathrm{m}^{2}\right)$ & $T_{o}(\mathrm{~K})$ & $n_{\mu}$ \\
\hline$\mu_{a}$ & $1.716 * 10^{-5}$ & 273 & 0.666 \\
$\mu_{v}$ & $1.12 * 10^{-5}$ & 350 & 1.15 \\
\hline
\end{tabular}

The mixture dynamic viscosity $\mu_{\text {mix }}\left(N . s / m^{2}\right)$ can be calculated using:

$\mu_{m i x}=\sum_{i=1}^{2} \frac{X_{i} \mu_{i}}{\sum_{j=1}^{2} X_{j} \Phi_{i j}}=\frac{X_{a} * \mu_{a}}{X_{a}+X_{v} * \Phi_{a v}}+\frac{X_{v} * \mu_{v}}{X_{v}+X_{a} * \Phi_{v a}}$ 
and the mixture thermal conductivity $k_{\text {mix }}(W / m K)$ can be calculated as:

$k_{\text {mix }}=\sum_{i=1}^{2} \frac{X_{i} k_{i}}{\sum_{j=1}^{2} X_{j} \Phi_{i j}}=\frac{X_{a} * k_{a}}{X_{a}+X_{v} * \Phi_{a v}}+\frac{X_{v} * k_{v}}{X_{v}+X_{a} * \Phi_{v a}}$

where $\Phi_{i j}$ component of mixture viscosity model and calculated as:

$\Phi_{i j}=\frac{1}{\sqrt{8}}\left(1+\frac{M_{i}}{M_{j}}\right)^{-1 / 2}\left[1+\left(\frac{\mu_{i}}{\mu_{j}}\right)^{0.5}\left(\frac{M_{i}}{M_{j}}\right)^{0.25}\right]^{2}$

The thermophysical properties of the air and water vapor can be determined at the film temperature $T$ (the average temperature of the body surface and the moist air environment). So, the Nusselt, Prandtl and Reynolds numbers are defined as:

$N u_{\text {mix }}=\frac{h * D_{\text {hyd }}}{k_{\text {mix }}}$

$P r_{\text {mix }}=\frac{\mu_{\text {mix }} * c_{p, m i x}}{k_{\text {mix }}}$

$R e_{\text {mix }}=\frac{\rho_{\text {mix }} * V * D_{\text {hyd }}}{\mu_{\text {mix }}}$

By applying the previous equations, we got six equations in three variables as following:

$$
\begin{aligned}
& 192.620=\mathrm{A}(31791.25)^{a}(0.705)^{b} \\
& 274.890=\mathrm{A}(15895.63)^{a}(0.708)^{b} \\
& 312.411=\mathrm{A}(31791.25)^{a}(0.710)^{b} \\
& 136.7=\mathrm{A}(15806.82)^{a}(0.713)^{b} \\
& 410.110=\mathrm{A}(31791.25)^{a}(0.713)^{b} \\
& 122.690=\mathrm{A}(15895.63)^{a}(0.713)^{b}
\end{aligned}
$$

\section{Experimental results and discussion}

\subsection{Effect of using HPT on HDH system under steady state conditions}

Figure 4 shows the effect of mass ratio on fresh water productivity at different feed water temperatures and constant air flow rate. It can be seen that, water productivity increases with increasing the feed water temperature or increasing the mass ratio. The maximum productivity was gained at $60^{\circ} \mathrm{C}$, mass ratio $=5$ and the lowest productivity was gained at $40^{\circ} \mathrm{C}$, mass ratio $=2$. The productivity at mass ratio $=5$ is increased by about $10 \%$ when the feed water temperature increased from $40^{\circ} \mathrm{C}$ to $50^{\circ} \mathrm{C}$, while the productivity is increased by about $140 \%$ when the feed water temperature increased from $40^{\circ} \mathrm{C}$ to $60^{\circ} \mathrm{C}$. This is contributed to the bonding connections between hot saltwater molecules get weak at the higher temperatures, so the introduced air can carry the vapor from the hot saltwater easily.

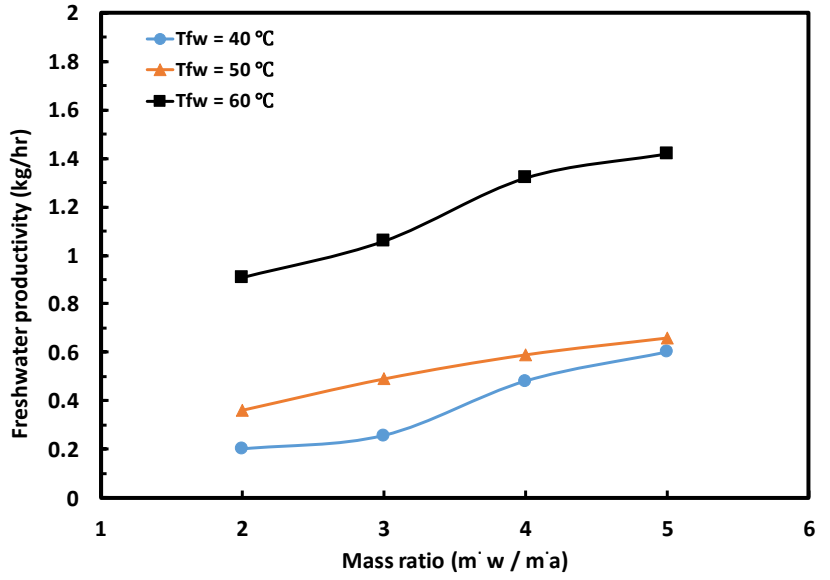

Figure 4: Effect of variable water flow rate on freshwater productivity at a different feed water temperature.

\subsection{Effect of Using PHT on HDH System under Unsteady State Conditions}

In this system, the experiments were implemented by using the solar energy. From the previous system (steady state system), the examined conditions used to get the best results for packing system, by using the electrical heater, were used again to examine the performance of $\mathrm{HDH}$ desalination unit by using the solar energy. For packing system, Figure 5 shows the solar irradiation in Port Said at 27 $7^{\text {th }}$ of July 2019 from 10:00 am to 5:00 pm and the productivity of fresh water produced from heating both the brine water and the ambient air by using the packing humidifier. Fresh water produced from the system increases with the time till noon due to the increase in solar radiation. The freshwater productivity from the system is $8.53 \mathrm{~kg} /$ day. The best results at steady state system were obtained at the feed brine water of 3.1 $\mathrm{L} / \mathrm{min}$ at $60{ }^{\circ} \mathrm{C}$, air flow rate of $52 \mathrm{~m}^{3} / \mathrm{h}$ and cooling water flow rate of $4.6 \mathrm{~L} / \mathrm{min}$. Those conditions were used again in the unsteady state system to examine the performance of the $\mathrm{HDH}$ desalination unit by using the packing humidifier.

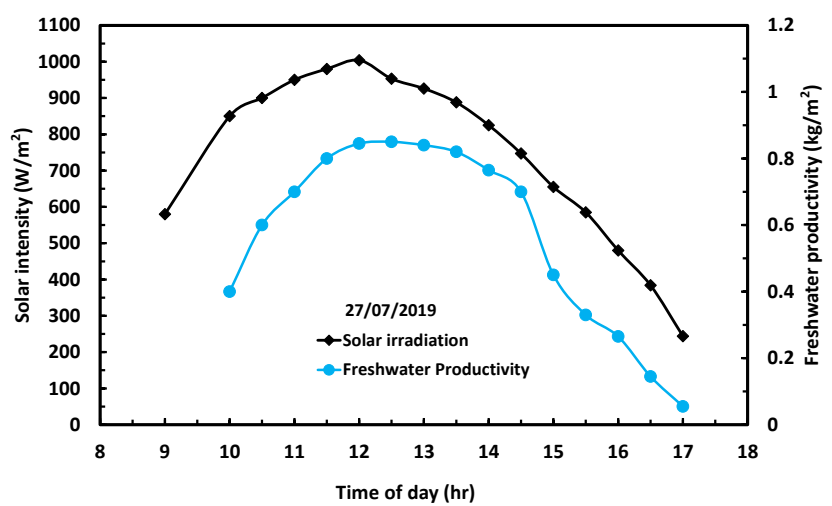

Figure 5: Hourly variation in the average solar irradiance versus freshwater productivity

\subsection{Mitigation Potential of $\mathrm{Co}_{2}$ Emissions}

The problem of global $\mathrm{CO}_{2}$ emissions is a serious problem faces the world. This problem can be solved by using renewable sources of energy like solar energy as a clean energy source to 
reduce the $\mathrm{CO}_{2}$ emission [23.24]. $\mathrm{HDH}$ systems, which utilize flat plate collector (FPC) for water heating for desalination is a good technique to decrease using electricity and, subsequently reducing carbon oxides emission levels. Reducing $\mathrm{CO}_{2}$ release level using $\mathrm{HDH}$ system is estimated as the following formula [25]:

$$
m_{t}=m_{e} * d E * t_{\text {life }}
$$

where $m_{t}$ is the reduction in the emission level of $\mathrm{CO}_{2}(\mathrm{~g})$ over its life cycle, $m_{e}$ is the average emission of $\mathrm{CO}_{2}(904 \mathrm{~g} / \mathrm{kWh})$ produced from a coal fuel-driven power station [26,27], $d E(\mathrm{kWh} /$ day) is the total energy saving per day of the proposed $\mathrm{HDH}$ system, and $t_{\text {life }}$ (day) is the economic lifespan of the HDH system, counted as 20 years $[28,29]$.

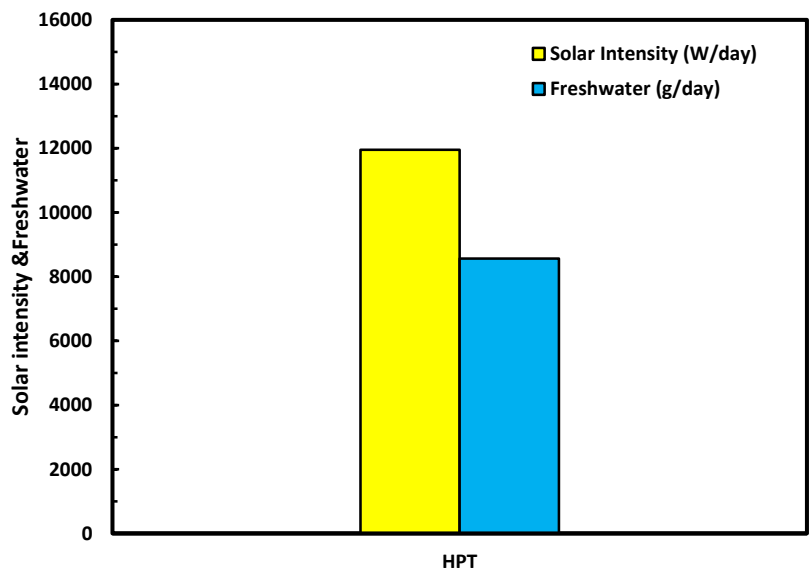

Figure 6: The daily accumulated solar intensity and accumulated daily potable water productivity against the humidifier configuration

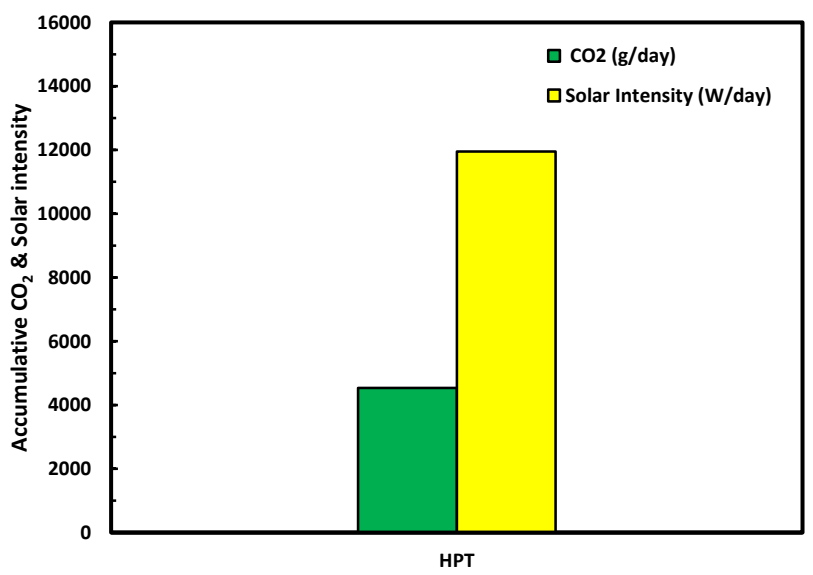

Figure 7: The daily accumulated solar intensity and saving of $\mathrm{CO}_{2}$ against the humidifier configuration

Figure 6 shows the solar intensity and the freshwater productivity for proposed $\mathrm{HDH}$ system along the day. This figure indicates that the accumulated daily irradiance values along the one day of July, $27^{\text {th }} 2019$, were $11,951 \mathrm{~W} /$ day, during the experiments with HPT. The daily production of freshwater is highly increased by the use of the HPT system. As the accumulated solar irradiance increases, the water productivity of the proposed HD system increases, and therefore it is noticeable in summer than in winter. The freshwater productivity produced from experiments at the HPT system is $8602 \mathrm{~g} /$ day. Figure 7 shows the accumulated solar intensity and the reduction in $\mathrm{CO}_{2}$ emissions thought the day. In the case of a HPT, the daily reduction of carbon dioxide $\mathrm{CO}_{2}$ as a result of using $\mathrm{HDH}$ system reached a value of $4600 \mathrm{~g}$. By solving the equations (eq. 43 to eq. 48) numerically, we got the empirical equation to calculate heat transfer coefficient outside the helical coil:

$N U_{\text {mix }}=0.936372 R e_{\text {mix }}^{0.606784} \operatorname{Pr}_{\text {mix }}^{1.014417}$

where $\mathrm{A}$ is 0.936372 , $\mathrm{a}$ is 0.606784 and $\mathrm{b}$ is 1.014417 .

\section{Conclusions}

From the presented experimental results based on proposed $\mathrm{HDH}$ system, it is indicated that the proposed HPT system can produce fresh potable water of $8.53 \mathrm{~kg} /$ day, to cut down overall $\mathrm{CO}_{2}$ release by about $4534 \mathrm{~g}$ in the day, respectively. It is also shown that the heat transfer outside the helical coil was enhanced by increasing the air flow rate and increasing the temperature of inlet humid air to condenser. The water productivity increased by increasing the outside heat transfer coefficient. A novel empirical equation for the the Nusselt number around the outer surface of concentric helical tube was induced by passing a mixture flow (air + water vapor) on the outer surface of the coil. The outside heat transfer coefficient can be evaluated from the induced following empirical equation:

$N U_{\text {mix }}=0.936372 \operatorname{Pr}_{\text {mix }}^{0.606784} \operatorname{Re}_{\text {mix }}^{1.014417}$

\section{Ethical issue}

Authors are aware of, and comply with, best practice in publication ethics specifically with regard to authorship (avoidance of guest authorship), dual submission, manipulation of figures, competing interests and compliance with policies on research ethics. Authors adhere to publication requirements that submitted work is original and has not been published elsewhere in any language.

\section{Competing interests}

The authors declare that there is no conflict of interest that would prejudice the impartiality of this scientific work.

\section{Authors' contribution}

All authors of this study have a complete contribution for data collection, data analyses and manuscript writing.

\section{References}

1 Moawed M. Experimental study of forced convection from helical coiled tubes with different parameters. Energy conversion and Management 52(2011) 1150-1156.

2 Essalhi N, Fguiri A, Marvillet C, Jeday MR. Design of helical coil condenser of small-capacity water/lithium Bromide absorption cooiling machine. International Journal of Hydrogen energy, volume 42, issue 13, 30 March 2017, pp8888-8897.

3 Salimpour MR. Heat transfer coefficients of shell and coiled tube heat exchangers. Experimental Thermal and Fluid Science 33(2009) 203207.

4 Shirgire ND, Kumar PV. Review on comparative study between helical coil and straight tube heat exchanger. IOSR Journal of 
Mechanical and Civil Engineering, volume 8, issue 2, (Jul - Aug 2013), pp 55-59.

5 Alimoradi A, Veysi F. Prediction of heat transfer coefficients of shell and coiled tube heat exchangers using numerical method and experimental validation. International journal of thermal sciences 107 (2016) 196-208.

6 Genic SB, Jacimovic BM, Jaric MS, Budimir NJ, Dobrnjac MM. Research on the shell side thermal performances of heat exchangers with helical tube coils. International journal of heat and mass transfer 55 (2012) 4295-4300.

7 Jamshidi N, Farhadi M, Ganji DD, Sedighi K. Experimental analysis of heat transfer enhancement in shell and helical tube heat exchangers. Applied Thermal Engineering 51 (2013) 644-652.

8 Ghorbani N, Taherian H, Gorji M, Mirgolbabaei H. Experimental study of mixed convection heat transfer in vertical helically coiled tube heat exchangers. Experimental Thermal and Fluid Science 34 (2010) 900-905.

9 Rahbar N and Esfahani JA, "Experimental study of a novel portable solar still by utilizing the heatpipe and thermoelectric module," Desalination, vol. 284, pp. 55-61, 2012.

10 Elhenawy Y, Elminshawy NA, Bassyouni M, Alanezi AA,Drioli E. Experimental and theoretical investigation of a new air gap membrane distillation module with a corrugated feed channel. J. Memb. Sci.. vol. 594. p. 117461. Jan. 2020.

11 THEODORE L. BERGMAN, ADRIENNE S. LAVINE, FRANK P. INCROPERA, DAVID P. DEWITT. Fundamentals of Heat and Mass Transfer. JOHN WILEY \& SONS.

12 Abd-Elmageed, A. A. I., Al-Hossainy, A. F., Fawzy, E. M., Almutlaq, N., Eid, M. R., Bourezgui, A., Bassyouni, M. Synthesis, characterization and DFT molecular modeling of doped poly (paranitroaniline-co-para-toluidine) thin film for optoelectronic devices applications. Optical Materials, (2020), 99, 109593.

13 Elminshawy, A., Morad, K., Elminshawy, N. A., \& Elhenawy, Y. Performance enhancement of concentrator photovoltaic systems using nanofluids. International Journal of Energy Research. (2020).

14 Dr. Marco Aurelio Dos Santos Bernardes. Developments in Heat Transfer.

15 Al-Hossainy, A. F., Zoromba, M. S., Abdel-Aziz, M. H., Bassyouni, M., Attar, A., Zwawi, M.,Slimane, A. B. Fabrication of heterojunction diode using doped-poly (ortho-aminophenol) for solar cells applications. Physica B: Condensed Matter, (2019), 566, 6-16.

16 Mabrouk, A. N., Elhenawy, Y., Abdelkader, M., \& Shatat, M. The impact of baffle orientation on the performance of the hollow fiber membrane distillation. Desalin. Water Treat, (2017), 58, 35-45.

17 Gaskill TJ. Heat transfer of a multiple helical coil heat exchanger using a microencapsulated phase change material slurry. Texas A\&M University, MSc. Thesis.

18 Mobarak, Y., Bassyouni, M., Almutawa, M. Materials selection, synthesis, and dielectrical properties of PVC nanocomposites. Advances in Materials Science and Engineering, 2013.

19 Elhady, S., Bassyouni, M., Mansour, R. A., Elzahar, M. H., AbdelHamid, S., Elhenawy, Y., \& Saleh, M. Y. Oily Wastewater Treatment Using Polyamide Thin Film Composite Membrane Technology. Membranes, (2020), 10(5), 84.

20 Enayotallahi R, Nates RJ, Anderson T. Characterizing the heat and mass transfer coefficients for a cross flow interaction of air and water. International Journal of Heat and Mass transfer 111 (2017) 94-104.

21 Zhang J, Gupta A, Baker J. Effect of Relative Humidity on the Prediction of Natural Convection Heat Transfer Coefficients. Heat Transfer Engineering, 28(4):335-342, 2007.

22 Tsilingiris PT. Thermophysical and transport properties of humid air at temperature range between 0 and $100{ }^{\circ} \mathrm{C}$. Energy Conversion and Management 49 (2008) 1098-1110.

23 Elhenawy Y, Hafez G, Abdel-Hamid S and Elbany M. Prediction and assessment of automated lifting system performance for multi-storey parking lots powered by solar energy. Journal of Cleaner Production. Vol. 266, 2020.
24 Sherif, S. A., Sadek, M. A., Ashour, F. H., Bassyouni, M. Effects of surface treatment of ground rice husk on the polyurethane based on castor oil. Polymers and Polymer Composites, (2009), 17(8), 481485.

25 Elminshawy NA, El-Ghandour M, Elhenawy ,Bassyouni YM, ElDamhogi DG, and Addas MF. Experimental investigation of a Vtrough PV concentrator integrated with a buried water heat exchanger cooling system. Sol. Energy. vol. 193. 2019.

26 Alanezi AA, Safaei MR, Goodarzi M, Elhenawy Y. The Effect of Inclination Angle and Reynolds Number on the Performance of a Direct Contact Membrane Distillation (DCMD) Process. Energies.13(11), 2824. 2020

27 Elsawy, K., Ibrahim, I. A., Abdelmotalip, A., \& Elhenawy, Y. (2020). Experimental investigation of air bubble/packing humidifier for desalination system driven by solar energy. International Journal, 9(5).

28 Abdel-Hamid SM, Al-Qabandi OA, Elminshawy NA., Bassyouni M, Zoromba MS, Abdel-Aziz MH, Mira H, Elhenawy Y. Fabrication and Characterization of Microcellular Polyurethane Sisal Biocomposites. Molecules.24(24). 4585. 2019.

29 Elminshawy NA, Gadalla MA, Bassyouni M, El-Nahhas K, Elminshawy A, Elhenawy Y. A novel concentrated photovoltaicdriven membrane distillation hybrid system for the simultaneous production of electricity and potable water. Renewable Energy. Vol.162. PP. 802-817. 2020.

\section{Author Profile}

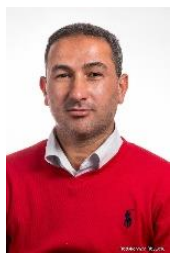

Dr. Y. Elhenawy was born in 19

Ph.D.: 2016 Port Said University Area of research: Renewable Energy, Membrane technology, nanotechnology and Water Desalination.

Universities: Port Said, Arab Acad. for Sc.Tech. 